\title{
Chemical Characterizations of Local Aluminum Kitchen Utensils in Burkina Faso
}

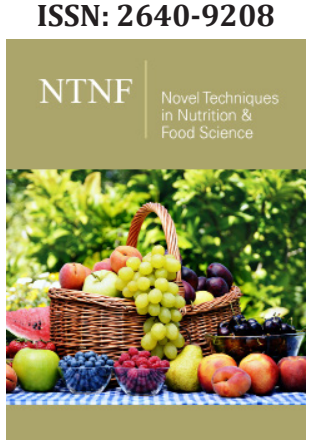

*Corresponding author: Jacques Sawadogo, National Centre for Scientific and Technological Research (CNRST), 01 BP 476 Ouagadougou 01, Burkina Faso

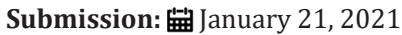

Published: 1 February 16, 2021

Volume 5 - Issue 4

How to cite this article: Jacques Sawadogo, Jean Boukari Legma. Chemical Characterizations of Local Aluminum Kitchen Utensils in Burkina Faso. Nov Tech Nutri Food Sci. 5(4). NTNF. 000618. 2021. DOI: 10.31031/NTNF.2021.05.000618

Copyright@ Jacques Sawadogo. This article is distributed under the terms of the Creative Commons Attribution 4.0 International License, which permits unrestricted use and redistribution provided that the original author and source are credited.

\section{Jacques Sawadogo ${ }^{1 *}$ and Jean Boukari Legma ${ }^{2}$}

${ }^{1}$ National Centre for Scientific and Technological Research (CNRST), 01 BP 476 Ouagadougou 01, Burkina Faso

${ }^{2}$ Saint Thomas Aquinas University (USTA), Faculty of Science and Technologies, 06 BP 10212 Ouagadougou 06, Burkina Faso

Abstract
As part of the reclamation of materials of Burkina Faso's artisanal origin, two samples of kitchen utensils
(artisanal pots) made of aluminum were collected and analyzed chemically. Craftsman poses the problem
of the quality of the finished products of the country especially when we know that they are used for
everyday cooking. This work is a contribution to the chemical characterization of craft pots in the central
region of Burkina Faso. The X-ray fluorescence (XRF) analysis indicates that the majority of the samples
studied contain approximately 87.3\% aluminum and a small amount of Silicon, Copper, Magnesium and
Zinc. Also, a measurement by colorimetry makes it possible to highlight the presence of aluminum in
solution.

\section{Introduction}

In Burkina Faso, handmade cooking utensils occupy a place of choice in the culinary art because they are better suited to the living conditions of the most vulnerable populations $[1,2]$. These utensils are generally obtained from aluminum recovery of all natures (piston, crankcase, aircraft wrecks, can, etc.) which founders classify as "hard," "soft" and "normal" alloys. Recycled materials, in addition to aluminum, have a diverse chemical composition. They contain trace amounts of heavy metals, which in the long-term expose populations to real risks of contamination [3-5]. Given the lack of predetermined rules for the preparation of the melting load and the diversity of aluminum waste, each alloy is unique. An evaluation of the development process, the analysis of formed layers, the chemical properties of kitchen utensils will allow an evaluation of the quality of these kitchen utensils. The main objective of this study is to present chemical results and mineralogical characterization of these kitchen utensils in various culinary environments, with specific objectives for the future to prevent potential hazards and on the other hand to evaluate their resistance to cooking by electrochemical methods.

\section{Materials and Methods}

\section{Sample material and preparations}

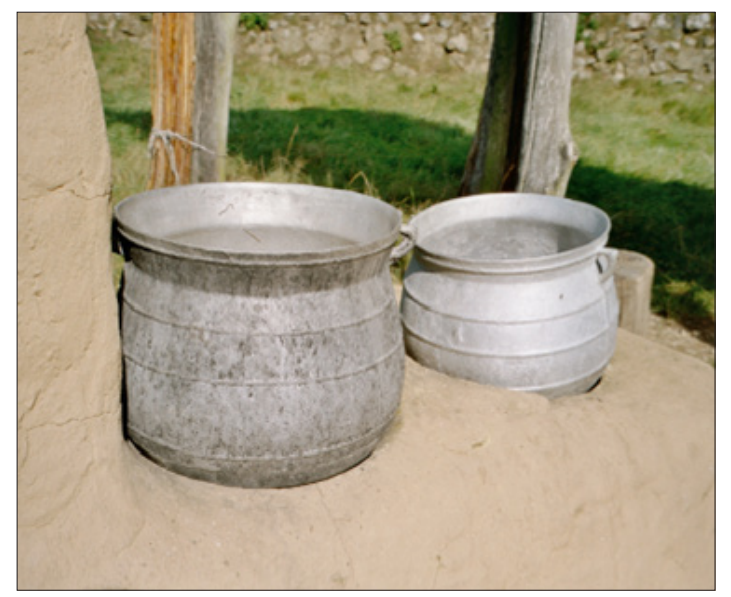

Figure 1: Finished products obtained (aluminum kitchen utensils). 
The two samples of cast aluminum alloys in the form of a washer were taken from two workshops in the town of Ouagadougou. Each alloy is unique. Depending on their chemical composition, the samples were called: Sample 1, which contains high levels of silicon and copper combined with low magnesium, and sample 2, which differs from the previous sample in low levels of silicon and copper with high magnesium. These samples were compared to aluminum from a European-made pressure cooker, called a control. The raw materials used in the manufacture of kitchen utensils (Figure 1) come from a wide variety of aluminum waste as shown in Figure 2.
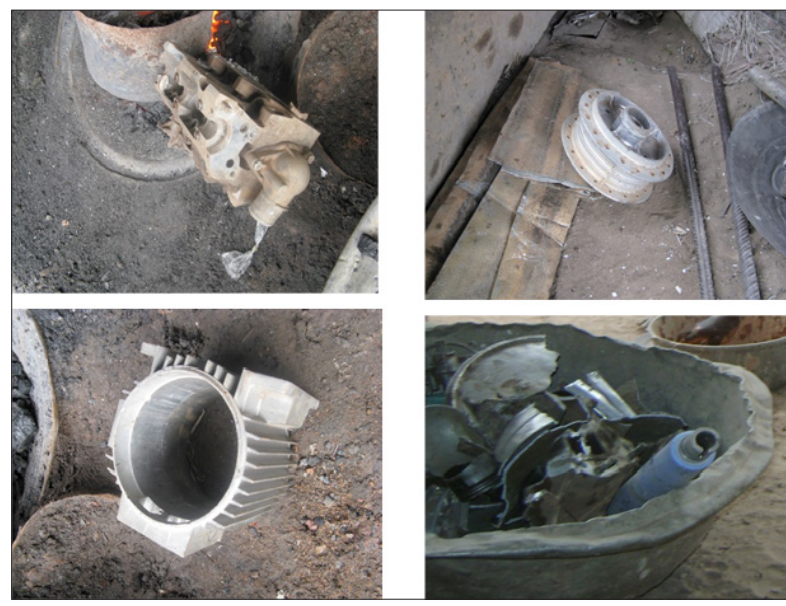

Figure 2: Raw materials used in the manufacture of kitchen utensils.

\section{Study and characterization environments}

To set up an operation similar to the Burkinabe kitchen, we placed the samples in Pyrex beakers containing the different media intended to understand the corrosion phenomena:

O: single tap water $(300 \mathrm{~mL})$ at room temperature; OS1: salted tap water (titrated to $3 \mathrm{~g} / \mathrm{l}$ or $9 \mathrm{~g} / \mathrm{l}$ ) at room temperature; $\mathrm{OS}_{2}$ : salted tap water (titrated to $3 \mathrm{~g} / \mathrm{l}$ or $9 \mathrm{~g} / \mathrm{l}$ ) at boiling temperature; OR: rice (5g in $250 \mathrm{ml}$ tap water); TC: tomato concentrate (140g); TF: fresh tomato (235g peeled and pureed). Since most of the cooking is done hot, the environments $\left(\mathrm{OS}_{2}, \mathrm{OR}, \mathrm{TC}\right.$ and $\left.\mathrm{TF}\right)$ are tested at the boiling temperature $\left(100{ }^{\circ} \mathrm{C}\right)$ to simulate real cooking conditions, temperature recommended by directive 97/48/EC.

\section{Result}

\section{Chemical analysis of alloys}

The results of the X-ray fluorescence spectrometry analysis of the selected samples were grouped together in Table 1, which contains the mass percentage results of the items analyzed by origin. There is a wide variety of chemical compositions of alloys resulting from the extreme diversity of the quality and quantity of the materials making up the aluminum waste deposit. Silicon, one of the major constituents of aluminum alloys intended for smelting, lowers the melting temperature of alloys, improves solubility and, consequently, limits critical risks (cracks in the metal) [6]. The copper content in sample 1 is out of standard and the zinc content in both samples is above standard. Aside from chloride and manganese, the other elements are present in small amounts in both samples. All samples have chloride levels well above those allowed by the French standard, this being probably a consequence of the melting load from which it is derived. The iron and manganese contents of alloys meet the standard. This confirms what we said earlier, namely that, given the lack of predetermined rules for the preparation of the melting load and the diversity of aluminum waste, each alloy is unique. The steel crucible where molten aluminum that remains at a high temperature (over $650^{\circ} \mathrm{C}$ ) for more than one hour is also a source of contamination.

Table 1: Chemical composition (XRF) in \% by mass of samples collected from smelters in Burkina Faso and maximum levels allowed by NF EN 601 July 2004.

\begin{tabular}{|c|c|c|c|c|c|c|c|c|c|c|c|c|c|}
\hline Elements Samples & Al & $\mathrm{Si}$ & $\mathrm{Fe}$ & $\mathrm{Cu}$ & $\mathbf{Z n}$ & Mg & $\mathrm{Cl}$ & $\mathrm{Cr}$ & Mn & $\mathbf{P b}$ & $\mathrm{Ni}$ & $\mathrm{Ti}$ & $\mathbf{Z r}$ \\
\hline Sample 1 & $\begin{array}{l}82,33 \\
\pm 0,33\end{array}$ & $\begin{array}{l}12,70 \\
\pm 0,24\end{array}$ & $\begin{array}{c}0,658 \\
\pm 0,017\end{array}$ & $\begin{array}{c}1,11 \\
\pm 0,016\end{array}$ & $\begin{array}{c}1,27 \\
\pm 0,150\end{array}$ & $\begin{array}{c}0,24 \\
\pm 0,03\end{array}$ & $\begin{array}{c}0,19 \\
\pm 0,03\end{array}$ & $\begin{array}{c}0,021 \\
\pm 0,006\end{array}$ & $\begin{array}{c}0,204 \\
\pm 0,001\end{array}$ & $\begin{array}{l}0 ; 0056 \\
\pm 0,006\end{array}$ & $\begin{array}{c}0,31 \\
\pm 0,01\end{array}$ & $\begin{array}{c}0,041 \\
\pm 0,007\end{array}$ & $\begin{array}{c}0,012 \\
\pm 0,001\end{array}$ \\
\hline Sample 2 & $\begin{array}{l}93,24 \\
\pm 0,34\end{array}$ & $\begin{array}{c}4,27 \\
\pm 0,15\end{array}$ & $\begin{array}{c}0,601 \\
\pm 0,016\end{array}$ & $\begin{array}{c}0,538 \\
\pm 0,011\end{array}$ & $\begin{array}{c}0,311 \\
\pm 0,010\end{array}$ & $\begin{array}{c}0,48 \\
\pm 0,03\end{array}$ & $\begin{array}{c}0,13 \\
\pm 0,03\end{array}$ & / & $\begin{array}{c}0,055 \\
\pm 0,007\end{array}$ & $\begin{array}{c}0,02 \\
\pm 0,004\end{array}$ & $\begin{array}{c}0,045 \\
\pm 0,004\end{array}$ & $\begin{array}{c}0,023 \\
\pm 0,006\end{array}$ & / \\
\hline Control & $\begin{array}{l}96,84 \\
\pm 0,34\end{array}$ & $\begin{array}{c}2,13 \\
\pm 0,11\end{array}$ & $\begin{array}{c}0,19 \\
\pm 0,010\end{array}$ & $\begin{array}{c}0,014 \\
\pm 0,003\end{array}$ & $\begin{array}{c}0,018 \\
\pm 0,002\end{array}$ & $<0,01$ & $\begin{array}{c}0,21 \\
\pm 0,03\end{array}$ & $<0,005$ & $<0,005$ & $<0,002$ & 0,011 & $<0,005$ & / \\
\hline $\begin{array}{l}\text { French Standard } \\
601 \text { of July } 2004\end{array}$ & Rest & 13,5 & 2 & 0,6 & 0,25 & 11 & $<0,05$ & 0,35 & 4 & $<0,05$ & 3 & 0,3 & 0,3 \\
\hline
\end{tabular}

Al: Aluminium; Si: Silicon; Fe: Iron; Cu: Copper; Zn: Zinc; Mg: Magnesium; Cl: Chloride; Cr: Chromium; Mn: Manganese; Pb: Lead; Ni: Nickel; Ti: Titanium; Zr: Zirconium 


\section{Chemical analysis of substrates}

The colorimetry allowed us to highlight the presence of $\mathrm{Al}^{3+}$ ions in the substrates. After having shown the possibility of the solution of aluminum alloys by attack in contact with the food environment, the search for food corrosion products in the food itself is necessary. The elements sought are aluminum, copper, zinc, silicon, and sometimes lead or tin. Their choice is even more justified now, following the observation of their chemical composition, of the attack essentially localized in the aluminum matrix and at the level of the interfaces of this matrix with the other phases. In this part of the study, cooking was extended up to 3 hours in order to increase the concentration of the ions resulting from the attack in the solutions. (Tables 2-5) present the results obtained for $\mathrm{O}, \mathrm{OS}_{2}, \mathrm{OR}$ and TC. These analyses clearly show that the quantities of metallic elements present in attack environments are all very low in the range of standards.

Table 2: Ion detection by colorimetry in $\mathrm{O}$ medium after $3 \mathrm{~h}$ of corrosion.

\begin{tabular}{|c|c|c|c|c|}
\hline Elements & $\mathbf{A l}^{3+}(\mathbf{m g} / \mathbf{l})$ & $\mathrm{Cl}^{(\mathbf{m g} / \mathbf{l})}$ & $\mathbf{F e}^{2+}(\mathbf{m g} / \mathbf{l})$ & $\mathrm{Cu}^{2+}(\mathbf{m g} / \mathbf{l})$ \\
\hline Samples & & & - & - \\
\hline Sample 1 & 5 & - & - & - \\
\hline Sample 2 & 4 & - & - & - \\
\hline Control & 5 & - & \\
\hline
\end{tabular}

Al: Aluminium; Cl: Chloride; Fe: Iron; Cu: Copper

Table 3: Ion detection by colorimetry in $\mathrm{OS}_{2}$ medium after $3 \mathrm{~h}$ of corrosion.

\begin{tabular}{|c|c|c|c|c|}
\hline Elements & $\mathbf{A l}^{3+}(\mathbf{m g} / \mathbf{l})$ & $\mathbf{C l}(\mathbf{m g} / \mathbf{l})$ & $\mathbf{F e}^{2+}(\mathbf{m g} / \mathbf{l})$ & \\
\hline Samples & & & $\mathbf{C u}^{2+}(\mathbf{m g} / \mathbf{l})$ \\
\hline Sample 1 & 40 & 2300 & - & - \\
\hline Sample 2 & 32 & 2300 & - & - \\
\hline Control & 40 & 2300 & - & - \\
\hline
\end{tabular}

Al: Aluminium; Cl: Chloride; Fe: Iron; Cu: Copper

Table 4: Ion detection by colorimetry in OR medium after $3 \mathrm{~h}$ of corrosion.

\begin{tabular}{|c|c|c|c|c|}
\hline Elements & $\mathbf{A l}^{3+}(\mathbf{m g} / \mathbf{l})$ & $\mathbf{C l}(\mathbf{m g} / \mathbf{l})$ & $\mathbf{F e}^{2+}(\mathbf{m g} / \mathbf{l})$ & \\
\hline Samples & & & $\mathbf{C u}^{2+}(\mathbf{m g} / \mathbf{l})$ & - \\
\hline Sample 1 & 50 & 2800 & - & - \\
\hline Sample 2 & 40 & 2800 & - & - \\
\hline control & 60 & 2800 & - \\
\hline
\end{tabular}

Al: Aluminium; Cl: Chloride; Fe: Iron; Cu: Copper

Table 5: Ion detection by colorimetry in TC medium after $3 \mathrm{~h}$ of corrosion.

\begin{tabular}{|c|c|c|c|c|}
\hline Elements & $\mathbf{A l}^{3+}(\mathbf{m g} / \mathbf{l})$ & $\mathbf{C l}(\mathbf{m g} / \mathbf{l})$ & $\mathbf{F e}^{2+}(\mathbf{m g} / \mathbf{l})$ & \\
\hline Sample & & & $\mathbf{C u}^{2+}(\mathbf{m g} / \mathbf{l})$ \\
\hline Sample 1 & 50 & 3000 & - & - \\
\hline Sample 2 & 40 & 3000 & - \\
\hline Control & 60 & 3000 & - \\
\hline
\end{tabular}

Al: Aluminium; Cl: Chloride; Fe: Iron; Cu: Copper

\section{Discussion}

The results show a significant presence of aluminum ions in the substrates. This presence poses the problem of human toxicity in the substrates. Assuming a loss of mass due to the oxidation of aluminum in the alloy, the toxicity of which is subject to controversy, which is then entirely transferred to the food, a person consuming for example $250 \mathrm{~g}$ of this rice would ingest $9.8 \mathrm{mg}$ of this metal.
To this quantity of aluminum from the pot is added that provided by food. For example, drinking water contains about $0.2 \mathrm{mg} . \mathrm{l}^{-1}$ of aluminum $[7,8]$ and rice contains about $1.7 \mu \mathrm{g} . \mathrm{g}^{-1}[9]$. Water and rice contributions are so low that the amount of aluminum ingested is relatively independent of the water-rice ratio. However, the toxicity standards adopted by some authors $[10,11]$ indicate a tolerable daily intake of $1 \mathrm{mg}$ per kilogram of body weight for humans. This 
dose is the maximum amount tolerable by the human body beyond which aluminum becomes toxic to it. This simplified assessment shows that we are far from the critical threshold for which human health is at risk. Based on this study, it can be concluded that alloys used in the manufacture of pots in Burkina Faso do not present any particular toxicological hazards. The data obtained comply with the standards and show their good quality and their possible use for cooking. The predominance of silicon in sample 1 is consistent with aggressiveness in the studied media and justifies their strong attack on this sample. This study made it possible to update the data of the literature and should support the agri-food and socio-economic interest of the manufacture of kitchen utensils in the center of Burkina Faso according to the area [12]. After some preliminary tests, the artisanal alloys of Burkina Faso are inert to the food with which they come into contact and we notice important consequences on the microstructure, especially at the interface between aluminium and other phases. These materials are therefore indeed usable in food.

\section{Conclusion}

This work is a contribution to the characterization of kitchen utensils in culinary environments, of two samples collected in two localities of central Burkina Faso (Ouagadougou). The chemical characteristics are dependent on the source of the kitchen utensil samples. So, the experiments we have just completed show that degradation is important in all environments, especially those containing rice. The data obtained comply with the standards and show their good quality and their possible use for cooking. The predominance of silicon in sample 1 is consistent with aggressiveness in the studied media and justifies their strong attack on this sample. This study made it possible to update the data of the literature and should support the agri-food and socio-economic interest of the manufacture of kitchen utensils in the center of Burkina Faso according to the area. After some preliminary tests, the artisanal alloys of Burkina Faso are inert to the food with which they come into contact and we notice important consequences on the microstructure, especially at the interface between aluminum and other phases. These materials are therefore indeed usable in food.

\section{References}

1. Sawadogo J, Nisol B, Bougouma B, Ramdé T, Boubié G, et al. (2014) Caractérisations chimiques des ustensiles de cuisine artisanale en aluminium fabriqués au Burkina Faso: cas de Ouagadougou. International Journal of Biological and Chemical Sciences 8(6): 2813-2827.

2. Sawadogo J, Bougouma M, Kabore A, Bambara D, Legma JB (2018) Electrochemical impedance spectroscopy characterization of kitchen ustensils and materials for local cooking in two culinary media. Scientific Study \& Research. Chemistry \& Chemical Engineering, Biotechnology, Food Industry 19(4): 375.

3. Shabestari S (2004) The effect of iron and manganese on the formation of intermetallic compounds in aluminum-silicon alloys. Materials Science and Engineering: A 383(2): 289-298.

4. Draissia M (2004) Structure and physico-chemistry of metastable aluminum-copper deposits produced by magnetron sputtering. Thesis, Badji-Mokhtar Annaba University, Algéria, p. 98.

5. Draissia M, Debili M, Millet JP (2005) Comportement à la corrosion du système de films minces aluminium-cuivre. Journal of New Materials for Electrochemical Systems 8(3): 229-233.

6. Bougouma M, Sawadogo J, Kaboré A, Bambara D, Aahamane A, et al. (2018) Analyse électrochimique du comportement des ustensiles de cuisine locaux dans l'eau de robinet et dans différents milieux culinaires. Afrique Science 14(1): 106-118.

7. Ndiaye MB, Coquillet B, Cissé IK (2012) Analysis of cooking utensils containing aluminum scrap in Senegal. Research Journal of Applied Sciences Engineering and Technology 4(4): 367-370.

8. Fekrache A, Debili MY, Lallouche S (2014) Structural characterization of a bulk and nanostructured Al-Fe system. Material in Technologize 48(5): 631-637.

9. Deqing W, Ziyuan S, Longjiang Z (2003) A liquid aluminum corrosion resistance surface on steel substrate. Applied Surface Science 214(1): 304-311.

10. Chen X, Geng H, Li Y (2006) Study on the eutectic modification level of Al-7Si Alloy by computer aided recognition of thermal analysis cooling curves. Materials Science and Engineering: A 419(1): 283-289.

11. Sawadogo J, Legma JB (2020) Electrochemical impedance spectroscopy (EIS) characterization of kitchen utensils used as materials for local cooking in two culinary media. Electrochemical Impedance Spectroscopy. IntechOpen, IntechOpen: 16.

12. Woodson G (1998) An interesting case of osteomalacia due to antacid use associated with stainable bone aluminum in a patient with normal renal function. Bone 22(6): 695-698.

For possible submissions Click below: 